Research Article

\title{
Evaluating the Resistance Performance of the VAEPC and the PAFRC Composites against a Low-Velocity Impact in Varying Temperature
}

\author{
Gwang-Hee Heo $\mathbb{D}^{\mathbb{D}},{ }^{1}$ Jong-Gun Park $\mathbb{D}^{2}{ }^{2}$ and Chung-Gil Kim ${ }^{2}$ \\ ${ }^{1}$ Department of International Civil and Plant Engineering, Konyang University, 121 Daehak-Ro, Nonsan-Si, Chungnam-Do, \\ Republic of Korea \\ ${ }^{2}$ Public Safety Research Institute, Konyang University, 121 Dachak-Ro, Nonsan-Si, Chungnam-Do, Republic of Korea
}

Correspondence should be addressed to Jong-Gun Park; 2630@hanmail.net

Received 8 October 2019; Revised 14 January 2020; Accepted 24 January 2020; Published 22 February 2020

Academic Editor: Robert Černý

Copyright (c) 2020 Gwang-Hee Heo et al. This is an open access article distributed under the Creative Commons Attribution License, which permits unrestricted use, distribution, and reproduction in any medium, provided the original work is properly cited.

\begin{abstract}
This paper aims to evaluate the resistance performance of the vinyl acetate ethylene polymer cement (VAEPC) composite and the polyvinyl alcohol fiber-reinforced cement (PAFRC) composite against a low-velocity impact in varying temperature. Their impact resistance performances are analyzed and compared with plain mortar after 28 days of age. Low-velocity impact tests were carried out under the various room temperatures of $-70^{\circ} \mathrm{C}, 70^{\circ} \mathrm{C}$, and $140^{\circ} \mathrm{C}$. Also, an INSTRON CEAST 9350 drop-tower system has been used to get the impact load, fracture energy, and displacement of the specimens while loading low-velocity impacts. From these tests, the failure pattern, shape, and strength of each test specimen were evaluated for the VAEPC, the PAFRC composite, and the plain mortar. Those test results showed that the flexural strength of both the VAEPC and the PAFRC composites has increased compared to that of the plain mortar. However, the compressive strength of the PAFRC composite decreased slightly after 28 days, while its flexural strength increased by $24.4 \%$ compared to that of the plain mortar. In addition, the drop test results show that PAFRC composite specimens have the highest impact fracture energy compared to other specimens at $-70^{\circ} \mathrm{C}, 70^{\circ} \mathrm{C}$, and $140^{\circ} \mathrm{C}$, whereas plain mortar specimens have their lowest. This is because the PVA fiber included in the PAFRC acts as a bridge to suppress crack propagation and to improve energy absorption performance, which helps it resist relatively better against impact. It is also known that while the VAEPC composite and the plain mortar were destroyed in a form of being perforated, the specimens of PAFRC composite were observed to some extent to suppress the perforation failures. Therefore, under a load of low-velocity impact, the resistance performance of the VAEPC composite and the plain mortar was proven to show brittle fracture behavior, while the PAFRC showed ductile fracture behavior in virtue of PVA fiber reinforcement which improved its flexural performance. According to the SEM observation which followed the tests, the PAFRC composite as a fiber-reinforced material of the hydrophilic material was found to show the most excellent interfacial bond adhesion compared to the other composite and the plain mortar. The PAFRC composite manufactured in the study has been proven to be very useful as a reinforcement material in both high and low temperature environments.
\end{abstract}

\section{Introduction}

There are many natural disasters and extreme cold and heat weather around the world, all caused by unexpected climate change. Also, the risk of explosion and impact due to terrorism or collision of vehicles, ships, aircrafts, etc. is gradually increasing, and there is always a possibility of accidents anytime. This causes many concrete structures to deteriorate. Therefore, all buildings and civil infrastructure facilities require high performance in order to resist against hostile environment. In particular, concrete structures should be designed to endure the unexpected impacts of climate change or careless accidents such as typhoons, earthquakes, explosions, and collisions, with high safety 
requirements $[1,2]$. Accordingly, the fiber-reinforced cement composites (FRCC) have been widely applied in many buildings and civil infrastructure facilities for decades to ensure their safety against external impacts [3-9].

Cement composite materials have excellent compressive strength, so they are most widely used in the construction of building and civil infrastructure facilities, but their tensile strength, flexural toughness, and ductility are relatively low $[10,11]$. Cement composites have been developed to improve the strength properties of concrete using VAE polymer or PVA in plain mortar, in order to increase the resistance to flexural performance and to improve brittle properties [12-15].

In addition, it is important to evaluate the safety of the structures under extreme condition (load, temperature, etc.) caused by natural factors such as typhoons, earthquakes, and human factors such as explosions and collisions. As the risk of concrete structures increases by being directly exposed to extreme external forces, FRCC has received a lot of attention as one of the methods to increase the impact resistance of concrete structures against high rapid loads such as typhoons, earthquakes, explosions, and collisions [16-27].

Currently, many researchers have performed intensive research on high-performance cement composites as one of the most effective ways to improve the properties of cement composite materials in order to effectively manage the brittle properties of cement composite materials and the existing structures [28-31]. Among these cement composites, highperformance fiber-reinforced cement composites have been developed. They exhibit high flexural toughness and energy absorption capacity by incorporating PVA fiber into plain mortar [32-34]. Accordingly, FRCC is expected to be used for various applications such as for repair and reinforcement materials and impact and energy absorption materials. Also, the VAEPC composites based on polymer composite materials have been reported to have superior effects on improving tensile strength, flexural strength, adhesiveness, permeability, abrasion resistance, and chemical resistance compared to plain mortar [35-38].

As mentioned above, although many researchers have confirmed that VAEPC and PAFRC composites increase the flexural performance and water-tightness as well as the impact resistance, researches on the impact fracture behavior under different temperatures of cement composites in extreme environments are rare. Information is needed on the impact resistance when exposed to such extreme environments. It is very important to evaluate the impact resistance of cement composites in extreme environments where high and low temperatures occur repeatedly. Therefore Banthia et al. examined the impact resistance of fiber-reinforced concrete under abnormal temperature conditions [39]. Also, Liu et al. [40] investigated the energy absorption and fracture characteristics through impact tests of AR-glass textile reinforced mortars (TRMs) at $-25^{\circ} \mathrm{C} \sim 100^{\circ} \mathrm{C}$. The experimental results showed that the variation of temperature did not affect the impact performance compared to other conditions. In addition, the flexural strength test results of high-performance slurry-filled steel fiber-reinforced cement composites, with respect to exposure to high temperatures, have been reported to decrease the flexural strength with increasing exposure temperature [41].
Recently, demand for construction in extreme heat regions such as Saudi Arabia, Kuwait, and Qatar (hottest in the world) has increased, and Antarctic bases has secured resource ownership in extreme regions such as Antarctica (the coldest in the world). As the interest in extreme heat and cold regions increases with base construction competition, so does the necessity of construction technology as well as the design of the related regions. The temperature control range of these regions is $-65^{\circ} \mathrm{C}$ to $75^{\circ} \mathrm{C}$. Based on the performance of existing facilities, it is necessary to simulate the temperature of the deserts in extreme heat and the south poles and north pole in extremes cold. The behavior properties and performance of existing structures should be evaluated by simulating the extreme loads (explosion, impact, temperature, etc.) caused in buildings and civil infrastructure facilities due to human and natural factors. Furthermore, material and structural performance needs to be verified with different temperatures using environmental chamber that can simulate the current environment. Until now, researches have been mainly conducted to evaluate the impact resistance of cement composites. There is not much about the evaluation of impact resistance performance in consideration of environmental factors such as temperature variations $[42,43]$. In particular, it is necessary to review fully the impact resistance performance with different temperatures of structures under extreme environments such as typhoons, earthquakes, explosions, and collisions. However, the aim of the paper is to evaluate the impact resistance performance with different temperature using environment chamber of VAEPC and PAFRC composites under low-velocity impact loading.

Therefore, the paper was written with the basic strength (compression, flexural) test of the cement composites using VAE polymer and PVA fiber. In order to examine the impact resistance with different temperatures, the impact failure behaviors of VAEPC and PAFRC composite specimens under low-velocity impact loads at the selected temperature conditions of $-70^{\circ} \mathrm{C}, 70^{\circ} \mathrm{C}$, and $140^{\circ} \mathrm{C}$ were measured and compared. After the low-velocity impact tests, failure pattern and grade of specimens were evaluated. In addition, the interfacial bonding state (IBS) was observed through a scanning electron microscope (SEM) images to investigate the surface shape of the fractured specimen after the strength test.

\section{Experimental Program}

2.1. Experimental Plans. As the mix design conditions and experimental contents of this study are shown in Table 1 , the W/C of VAEPC composites and plain mortar were at $40.0 \%$ and that of PAFRC composites was at $44.0 \%$ to obtain good enough workability for this special experimental test. The target average compressive strength was about $40 \mathrm{MPa}$ at 28 days of age. Compressive strength and flexural strength were planned to be measured to show test results. In addition, the low-velocity impact tests are also conducted to evaluate the impact resistance performance of VAEPC, PAFRC composites, and plain mortar at selected temperature conditions of $-70^{\circ} \mathrm{C}, 70^{\circ} \mathrm{C}$, and $140^{\circ} \mathrm{C}$.

2.2. Materials. The physical properties of materials are shown in Table 2. For mixing of mortar, the ordinary 
TABLE 1: Mix design conditions and experiment contents.

\begin{tabular}{|c|c|c|}
\hline Section & Factors & Levels \\
\hline \multirow{8}{*}{ Mix design conditions } & Fiber dosage (\%) & $0,1.0$ \\
\hline & Fiber content $\left(\mathrm{kg} / \mathrm{m}^{3}\right)$ & 0,13 \\
\hline & Displacement ratio (\%) & 0,10 \\
\hline & Displacement content $\left(\mathrm{kg} / \mathrm{m}^{3}\right)$ & 0,61 \\
\hline & $\mathrm{W} / \mathrm{C}(\%)$ & Plain mortar (PM), VAEPC: 40.0; PAFRC: 44.0 \\
\hline & $C: S$ & $1: 2$ \\
\hline & $\mathrm{P} / \mathrm{C}$ : polymer-cement ratio (\%) & 10 \\
\hline & $\begin{array}{l}\text { Target average compressive strengths at } 28 \text { age } \\
\qquad(\mathrm{MPa})\end{array}$ & 40 \\
\hline \multirow{2}{*}{ Experiment contents } & Hardened state & Compressive and flexural strength (MPa): 28 days \\
\hline & Low-velocity impact tests & Temperature conditions: $-70,70$, and $140^{\circ} \mathrm{C}$ \\
\hline
\end{tabular}

TABle 2: Physical properties of materials.

\begin{tabular}{|c|c|}
\hline Materials & Properties \\
\hline Cement & Ordinary Portland cement (type I), density: $3.15 \mathrm{~g} / \mathrm{m}^{3}$, fineness: $3,620 \mathrm{~cm}^{2} / \mathrm{g}$ \\
\hline $\begin{array}{l}\text { Fine } \\
\text { aggregate }\end{array}$ & Density: $2.6 \mathrm{~g} / \mathrm{m}^{3}$ \\
\hline PVA fiber & 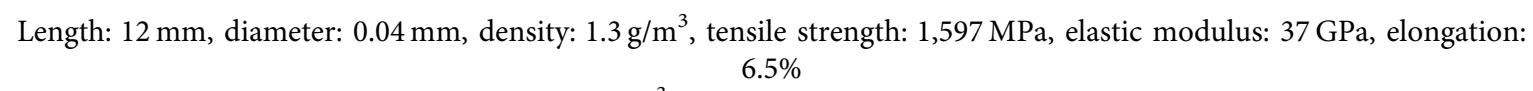 \\
\hline VAE polymer & $\begin{array}{c}\text { Appearance: white powder, density: } 0.47 \sim 0.59 \mathrm{~g} / \mathrm{m}^{3} \text {, average size distribution: } 0.5 \sim 8 \mu \mathrm{m} \text {, main ingredient: Vinyl acetate } \\
\text { ethylene }\end{array}$ \\
\hline
\end{tabular}

Portland cement (type I) was used. It has a specific gravity of 3.15 and fineness of $3,620 \mathrm{~cm}^{2} / \mathrm{g}$. The specific gravity of fine aggregate was 2.60. No coarse aggregate was used in any specimens. The mix proportions and compressive strength of mortars are shown in Table 3. The specimens of PAFRC composite used in the paper are $V_{\mathrm{f}}=1.0 \%$ but are not counted in the weight, which corresponds to $13 \mathrm{~kg}$ of PVA fiber in $1 \mathrm{~m} 3$ of plain mortar (PM). In case of the specimens of VAEPC composite, $10 \%$ of the cement weight was substituted for the mixing ratio, and $61.0 \mathrm{~kg}$ of VAE polymer was used for $1 \mathrm{~m}^{3}$ of plain mortar (PM). The ratio of cement to fine aggregate $(\mathrm{C}: \mathrm{S})$ was set at $1: 2$, and the ratio of polymer to cement $(\mathrm{P} / \mathrm{C})$ was set at $10 \%$. The mix proportion of plain mortar was designed to achieve a target compressive strength of about $40 \mathrm{MPa}$ at the age of 28 days. Figure 1 shows the shape of the VAE polymer and PVA fiber used in the study.

\subsection{Testing Methods}

2.3.1. Compressive and Flexural Tests. Figure 2 shows the installation of equipment and specimens used in this test for compressive and flexural strength tests. For the compression test, specimens were prepared individually using cubic molds of $40 \times 40 \times 40 \mathrm{~mm}$ and compression tests were carried out using Universal Testing Machine (INSTRON 5982). The cross-head speed (loading velocity) was about $0.50 \mathrm{~mm} /$ min and was maintained throughout the tests. The flexural testing was performed on a $40 \times 40 \times 160 \mathrm{~mm}$ screw-type specimen on the basis of a three-point loading (TPL) $[44,45]$. The span was $120 \mathrm{~mm}$ and height $40 \mathrm{~mm}$. The flexural stress $\left(f_{\mathrm{r}}\right)$ was obtained by using the following equation:

$$
f_{\mathrm{r}}=\frac{3 P L}{2 b h^{2}}
$$

where $P$ is the maximum load $(\mathrm{N}), L$ is span length $(\mathrm{mm})$, and $b$ and $h$ are width $(\mathrm{mm})$ and height $(\mathrm{mm})$ of beams, respectively.

2.3.2. Impact Test. The specifications of the drop-weight impact tester are shown in Table 4. The drop-weight impact tester installed for low-velocity impact tests is shown in Figure 3. The drop-weight impact tester used the INSTRON CEAST 9350 to obtain the impact load, fracture energy, displacement, and time of the specimens under low-velocity impact loads. The specimens were settled, low-velocity impact load was applied to the center of specimens, and a hemispherical weight of $21.3 \mathrm{kN}$ was dropped at the height of $144 \mathrm{~mm}$. The drop velocity at the point of impact was about $1.67 \mathrm{~m} / \mathrm{s}$ as the free drop velocity, and the impact energy applied was about $3.0 \mathrm{~J}$. The impact load is automatically measured when the impact is applied to the specimen by means of a load cell installed in the tub of the drop weight, and the impact fracture energy is converted through the measured load. The data from the drop-weight impact tester were collected using computer software as the impact data measurement connected to the low-velocity impact tests. The temperature control chamber can be used to control the internal temperature from $-170^{\circ} \mathrm{C}$ to $250^{\circ} \mathrm{C}$ using thermoregulator. Low-velocity impact tests were conducted at $-70^{\circ} \mathrm{C}, 70^{\circ} \mathrm{C}$, and $140^{\circ} \mathrm{C}$ by adjusting at room temperature (RT). Liquefied nitrogen was used for low temperature, while a heater was used for high temperature. At the temperature of $-70^{\circ} \mathrm{C}$, the test was carried out after cooling for 1 hour and heated to $70^{\circ} \mathrm{C}$ and $140^{\circ} \mathrm{C}$ for one hour in the oven. 
TABLE 3: Mix proportions of mortars.

\begin{tabular}{|c|c|c|c|c|c|c|c|}
\hline \multirow{2}{*}{ Type of mortars } & \multirow{2}{*}{$\mathrm{W} / \mathrm{C}(\%)$} & \multirow{2}{*}{$\mathrm{C}: \mathrm{S}$} & \multicolumn{5}{|c|}{ Unit weight $\left(\mathrm{kg} / \mathrm{m}^{3}\right)$} \\
\hline & & & Water & Cement & Fine aggregate & $V_{\mathrm{f}}$ & $\mathrm{P} / \mathrm{C}$ \\
\hline PAFRC & 44.0 & & 293 & 667 & 1334 & 13 & - \\
\hline VAEPC & 40.0 & $1: 2$ & 267 & 606 & 1334 & - & 61.0 \\
\hline Plain mortar & 40.0 & & 267 & 667 & 1334 & - & - \\
\hline
\end{tabular}

Note: C:S-cement vs fine aggregate, $V_{\mathrm{f}}-\mathrm{PVA}$ fiber volume, $\mathrm{P} / \mathrm{C}-$ polymer to cement ratio.

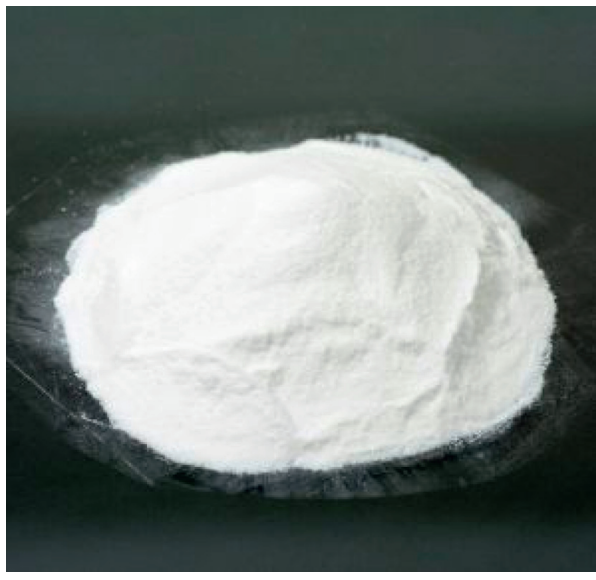

(a)

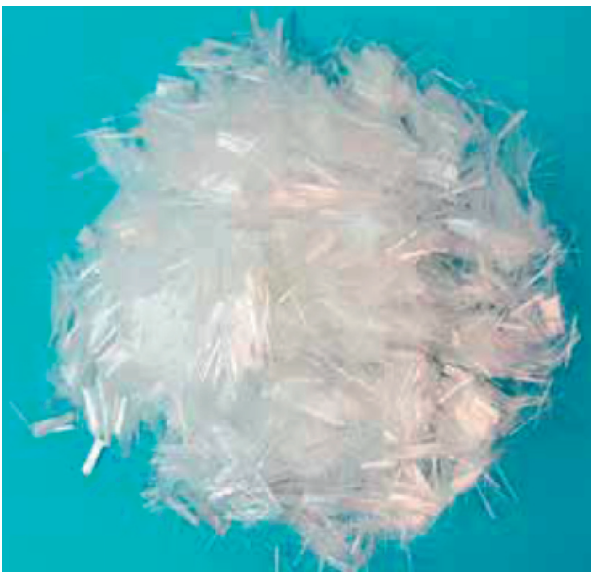

(b)

FIgURe 1: Shapes of VAE polymer and PVA fiber. (a) VAE polymer. (b) PVA fiber.

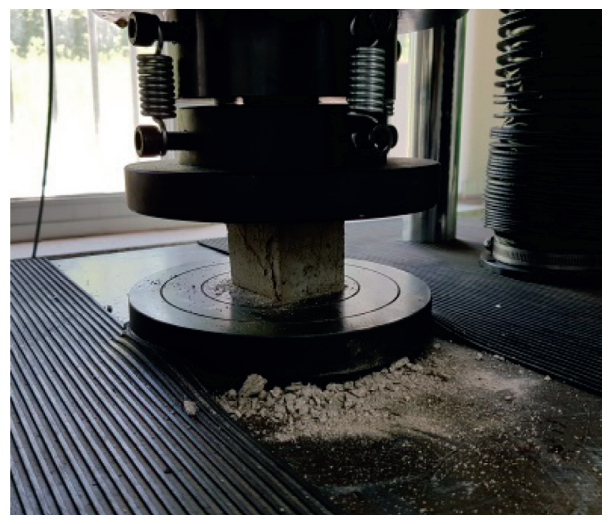

(a)

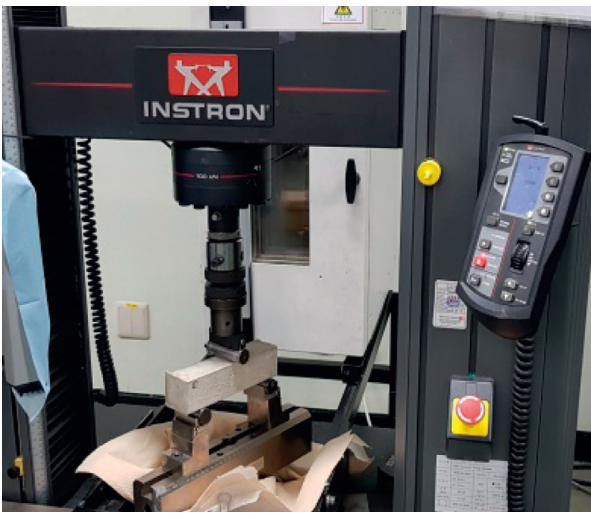

(b)

Figure 2: Compressive and flexural tests. (a) Compressive test. (b) Flexural test.

TABLE 4: Specifications of the drop-weight impact tester.

\begin{tabular}{|c|c|}
\hline Method & Specifications \\
\hline Force transducer capacity & $22,45,90 \mathrm{kN}$ \\
\hline Range of temperature & From $-170^{\circ} \mathrm{C}$ to $250^{\circ} \mathrm{C}$ \\
\hline Data acquisition & Force, energy, displacement, velocity, time \\
\hline High-speed data acquisition rates & $\mathrm{Up}$ to $2 \mathrm{MHz}$ \\
\hline
\end{tabular}




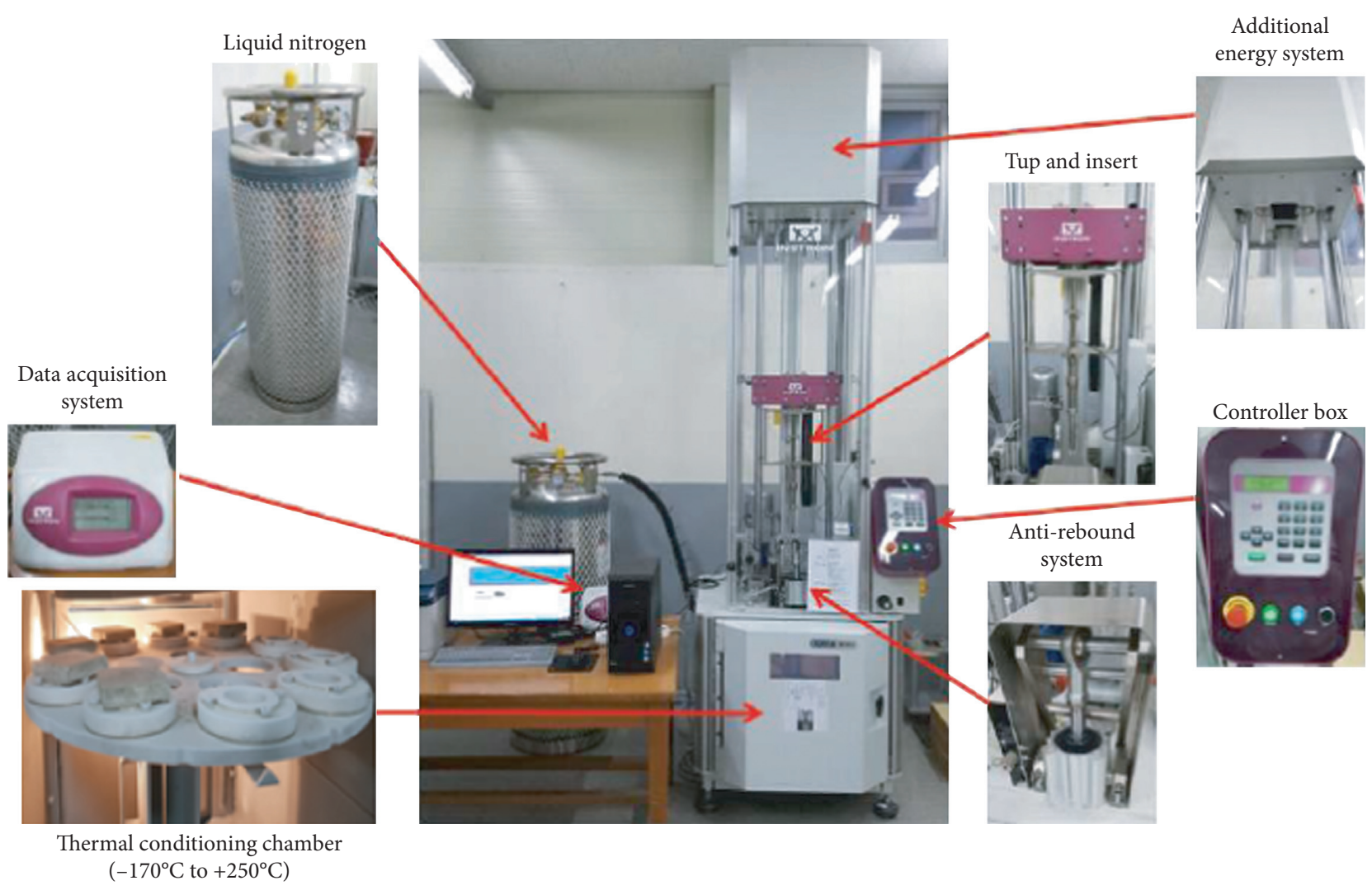

FIgURE 3: Drop-weight impact tester (INSTRON CEAST 9350).

Low-velocity impact tests were performed three times for each specimen under selected temperature conditions. The energy absorption (toughness) can be calculated by the "average of the area" under the load-displacement curves $[40,46]$. The energy absorption $\mathrm{U}$ was as follows:

$$
U=\int_{t=0}^{t=t^{\prime}} P(t) \cdot v(t) \mathrm{d} t \approx \sum P(t) \cdot \Delta \mathrm{d}(t)
$$

where in above expression " $t$ " " is the time increment and $P(t)$ and $v(t)$ are the impact load and speed at certain timestep " $t$." The " $\Delta \mathrm{d}(t)$ " is the impact displacement increment during the load processing.

2.4. Specimens Preparation. Specimens preparation for lowvelocity impact tests at selected temperature conditions is shown in Table 5. The specimens for low-velocity impact tests by each mix proportion were uniformly $60 \times 60 \mathrm{~mm}$ in size and $10 \mathrm{~mm}$ thick. Three specimens for each different temperature condition, 27 specimens in total, were prepared, then demolded in a grid-shaped device, and cured under the air-drying state until one day before the tests.

2.5. SEM Observation. In order to observe the fractured surface tomography of VAEPC and PAFRC composites and plain mortar specimens after the strength test, the fractured fragments of specimens were dried under the vacuum state, coated with platinum, and scanned with the scanning electron microscope (SEM) (model name: MIRA LMH, Tescan Ltd).

\section{Results and Discussion}

3.1. Evaluation Results of Mechanical Properties. The evaluation results of mechanical properties for compressive and flexural strengths at 28 days are shown in Table 6. From the test results, the compressive strength was found to exceed the target strength for PAFRC composites and plain mortar. At 28 days of age, PAFRC and VAEPC composites exhibited compressive strengths of $48.9 \mathrm{MPa}$ and $35.5 \mathrm{MPa}$, respectively. The compressive strength of PAFRC composites was about the same or slightly lower than that of plain mortar, while the VAEPC composites showed a somewhat lower compressive strength of about $71.3 \%$. At the age of 28 days, the flexural strength of PAFRC composite was $6.07 \mathrm{MPa}$ and VAEPC composite was $5.00 \mathrm{MPa}$, and flexural strength of plain mortar was $4.88 \mathrm{MPa}$. However, the flexural strength ratio to compressive strength was about $1 / 8.0$ for PAFRC composites and about $1 / 7.1$ for VAEPC composites. The flexural strength was shown to be the highest for PAFRC composites in the order of PAFRC $>$ VAEPC $>$ plain mortar.

The flexural stress and displacement results obtained from the flexural tests for three specimens are shown in Table 7. Figure 4 shows the flexural stress and displacement curves obtained from flexural strength test for three specimens. As shown in Figure 4(a), PAFRC composites showed a slight decrease in the stress after the maximum load, and it 
TABLE 5: Specimens for low-velocity impact tests.

\begin{tabular}{|c|c|c|c|}
\hline Temperature condition $\left({ }^{\circ} \mathrm{C}\right)$ & $\begin{array}{c}\text { Type of mortars } \\
\text { Total }\end{array}$ & Size and thickness (mm) & $\begin{array}{c}\text { Number of specimens } \\
27\end{array}$ \\
\hline \multirow{3}{*}{-70} & PAFRC & \multirow{3}{*}{$60 \times 60 \times 10 \mathrm{~mm}^{3}$} & 3 \\
\hline & VAEPC & & 3 \\
\hline & Plain mortar & & 3 \\
\hline \multirow{3}{*}{70} & PAFRC & \multirow[b]{6}{*}{$60 \mathrm{~mm}$} & 3 \\
\hline & VAEPC & & 3 \\
\hline & Plain mortar & & 3 \\
\hline \multirow{3}{*}{140} & PAFRC & & 3 \\
\hline & VAEPC & & 3 \\
\hline & Plain mortar & & 3 \\
\hline
\end{tabular}

TABLE 6: Results of mechanical properties for compressive and flexural strengths.

\begin{tabular}{lccc}
\hline Type of mortars & & Strength $(\mathrm{MPa})$ & $f_{\mathrm{r}}$ \\
& $\mathrm{f}_{\mathrm{cu}}$ & 6.07 & $\mathrm{f}_{\mathrm{cu}} / f_{\mathrm{r}}$ \\
\hline PAFRC (a) & 48.9 & 5.00 & 8.0 \\
VAEPC (b) & 35.5 & 4.88 & 7.1 \\
Plain mortar (c) & 49.8 & $124.4 \%$ & 10.2 \\
Ratio to increase/decrease (a/c) & $98.2 \%$ & $102.5 \%$ & - \\
Ratio to increase/decrease (b/c) & $71.3 \%$ & - \\
\hline
\end{tabular}

${ }^{*} f_{\text {cu }}$ : average of measured compressive strength at 28 days. $f_{\mathrm{r}}$ : average of measured flexural strength at 28 days.

TABLE 7: Flexural stress and displacement results obtained from the flexural tests.

\begin{tabular}{lccc}
\hline Type of mortars & No. of specimens & Flexural stress $(\mathrm{MPa})$ & Displacement at maximum load (mm) \\
\hline \multirow{3}{*}{ PAFRC } & 1 & 6.07 & 0.40 \\
& 2 & 6.80 & 0.90 \\
VAEPC & 3 & 5.14 & 0.41 \\
& 1 & 4.24 & 0.62 \\
Plain mortar & 2 & 5.06 & 0.35 \\
& 3 & 5.48 & 0.79 \\
& 1 & 4.88 & 0.37 \\
\end{tabular}

maintained the behavior to a certain extent of displacement in the state where the flexural stress was lowered up to about 19 to $40 \%$ of the maximum load. The slope of the descent gradually decreased and the displacement increased. This is because PVA fiber prevents the growth of cracks by cross and rapid brittle fracture due to the bridge effect of PVA fiber through crack dispersion. On the other hand, as shown in Figures 4(b) and 4(c), VAEPC composites and plain mortar draped abruptly after the maximum flexural stress and there was almost no displacement after the maximum flexural stress.

Figure 5 shows the fracture shape and appearance after the compression test on each specimen. As seen in Figure 5(a), the PVA fiber is very densely spread out, and it was confirmed that it is evenly distributed along the crack surface. The failure mechanism of fiber was found to be mainly due to fiber pullout rather than fiber fracture. The crack width was noticeably wider and maintained a large crack. This is considered to be due to the prevention of sudden brittle failure due to the bridge role between the PVA fibers inside the specimen. On the other hand, in Figure 5(b), the VAEPC composite showed a very smooth fracture surface due to the improvement of the bonding force by filling the pores with polymer film formation, but many microcracks and air voids were formed. However, the plain mortar was suddenly destroyed with small noises as the fragments were shattered by the central rupture in the center of the specimen height due to the vertical crack.

\subsection{Evaluation Results of Impact Resistance}

3.2.1. Failure Pattern and Grade. Drop-weight impact test is to examine the fracture behavior of the impact applied to the specimen vertically and to find the impact fracture energy according to the relationship between the impact force and time. Unlike the static load, the failure behavior of concrete under impact load does not transfer to the whole specimen due to the impact applied when high strain rate loads are applied, and shows local failure behavior. These local fracture shapes are largely classified into three types: penetration, scabbing, and perforation. Many researchers have been made on cement composites that improve flexural toughness and impact resistance by incorporating a variety fibers or 

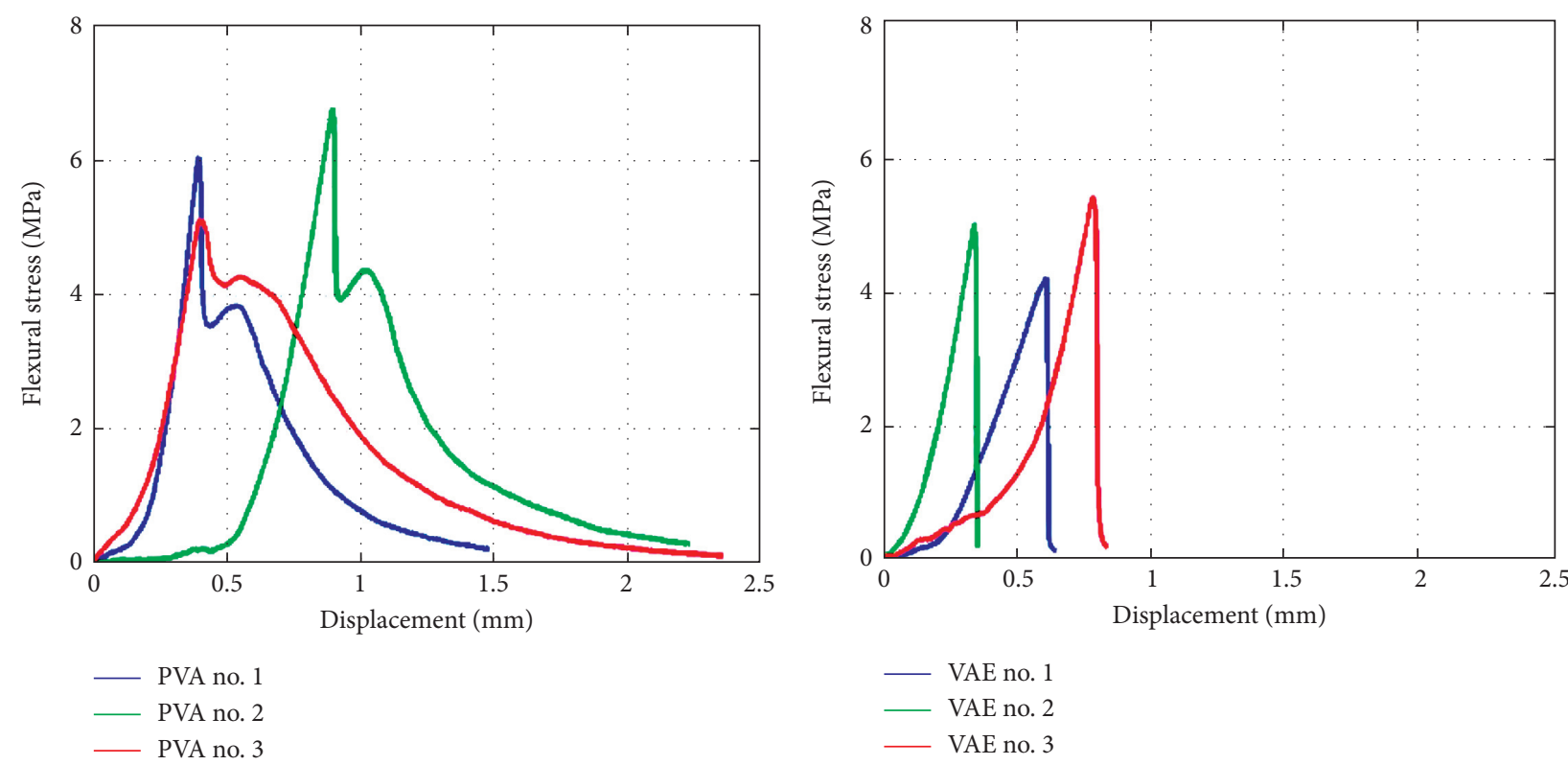

(a)

(b)

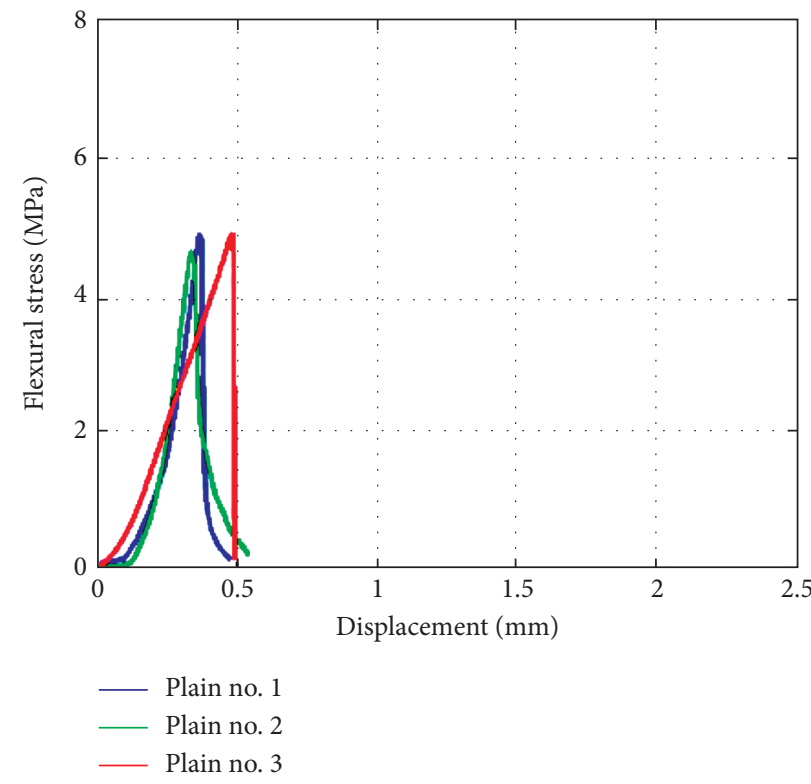

(c)

FIGURE 4: Flexural stress and displacement curves of mortar for each specimen. (a) PAFRC. (b) VAEPC. (c) Plain in mortar.
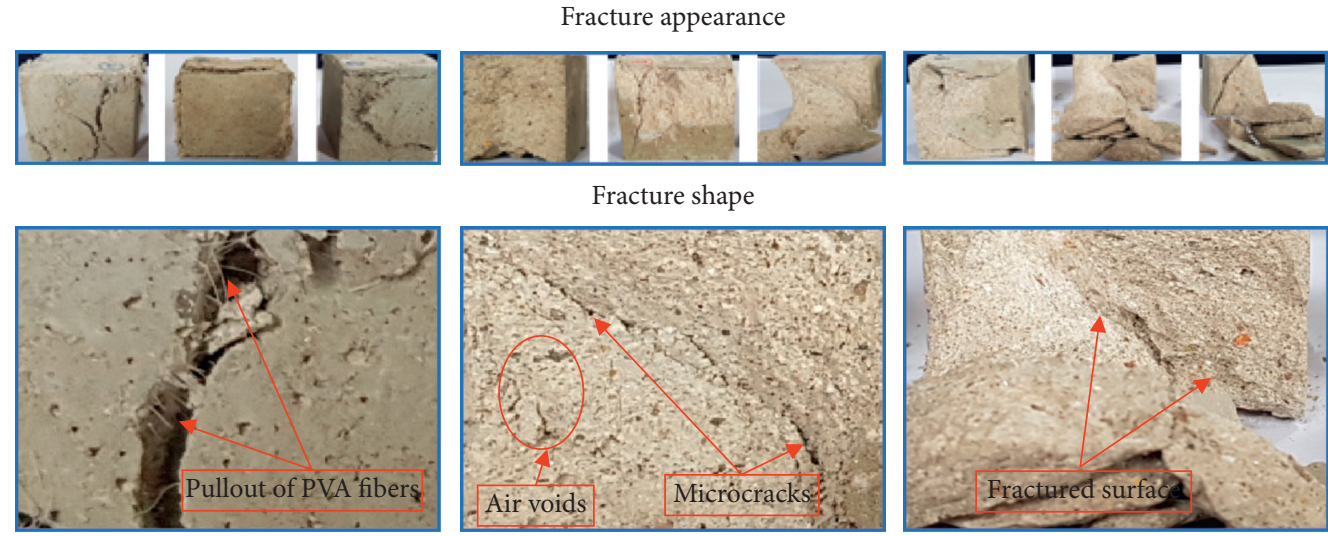

FIGURE 5: Fracture shape and appearance after compressive strength tests. (a) PAFRC. (b) VAEPC. (c) Plain mortar. 


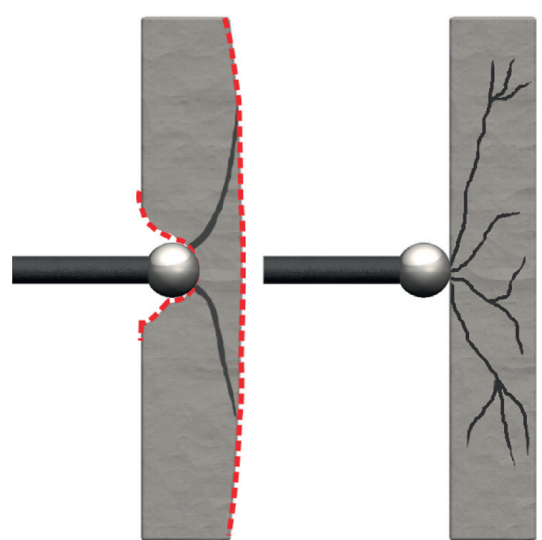

(a)

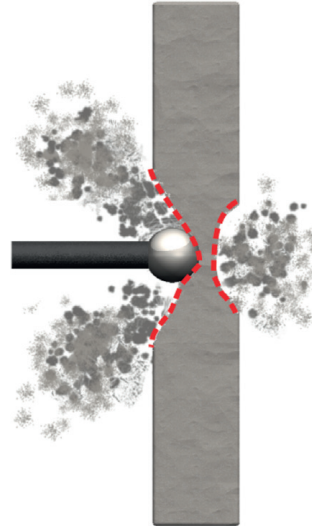

(b)

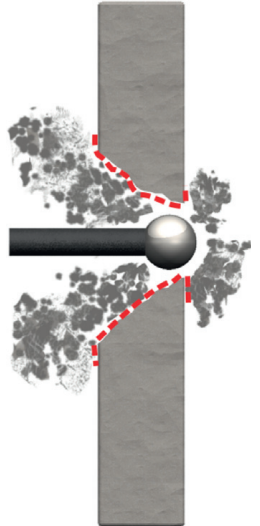

(c)

Figure 6: Failure pattern and grade by impact. (a) Penetration. (b) Scabbing. (c) Perforation.

TABle 8: Failure pattern of the specimens.

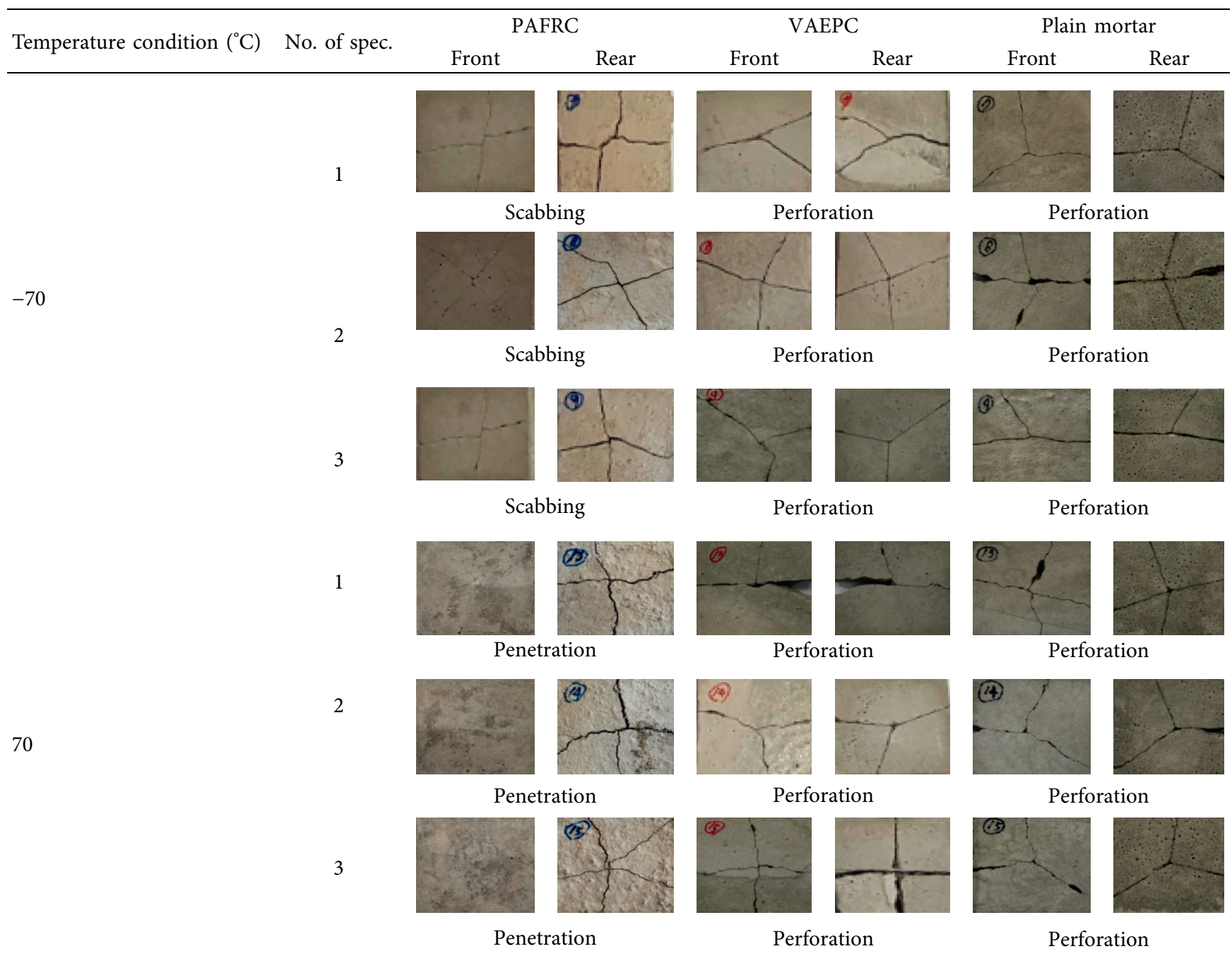


TABle 8: Continued.

Temperature condition $\left({ }^{\circ} \mathrm{C}\right)$ No. of spec.

TABLE 9: Summary of the low-velocity impact test results under different temperatures.

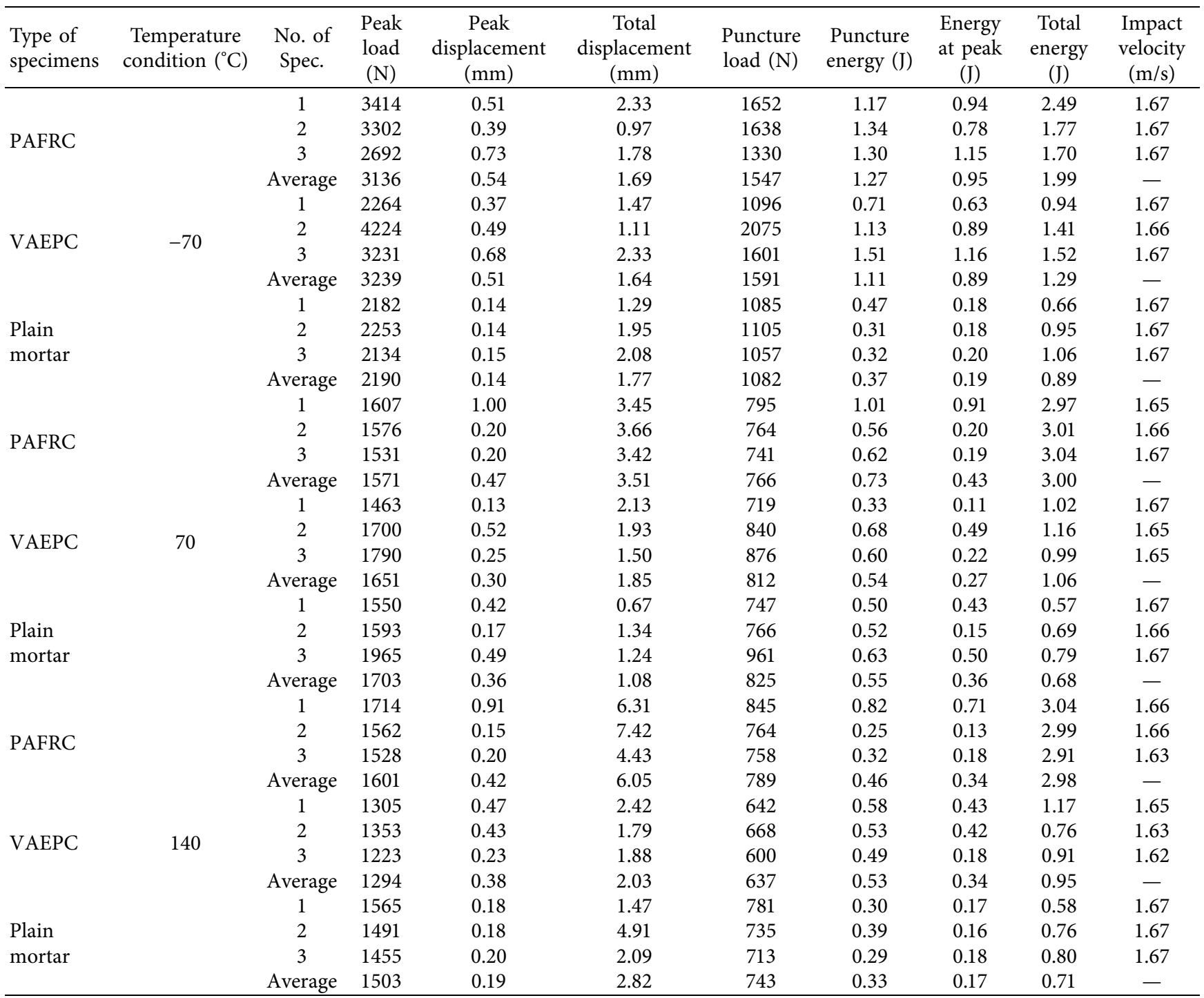




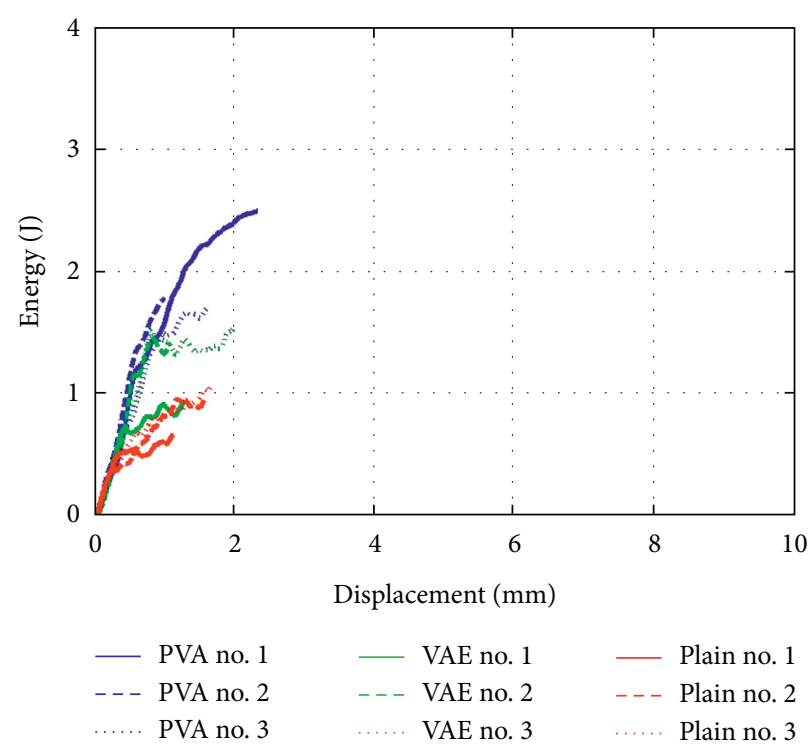

(a)

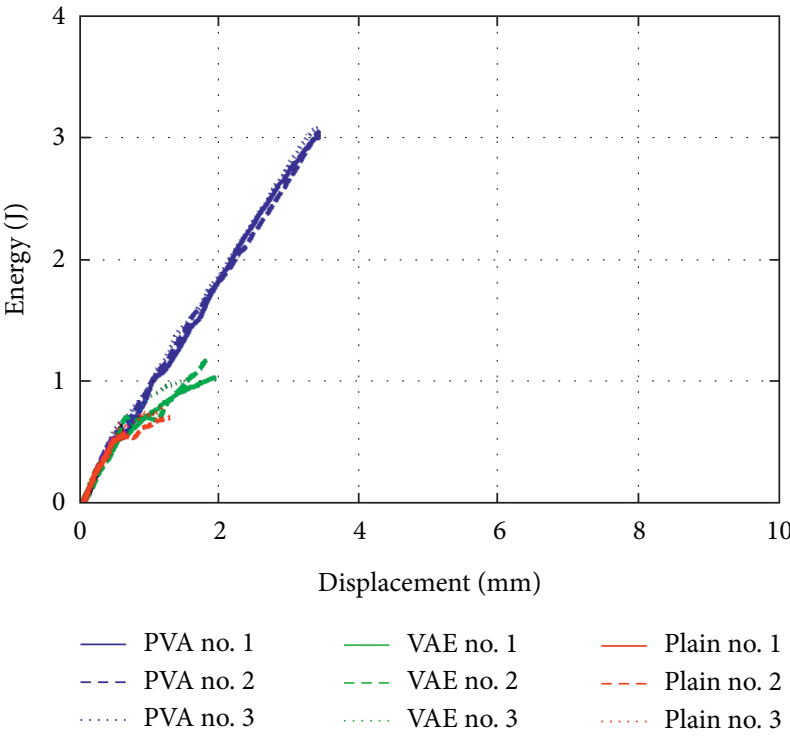

(b)

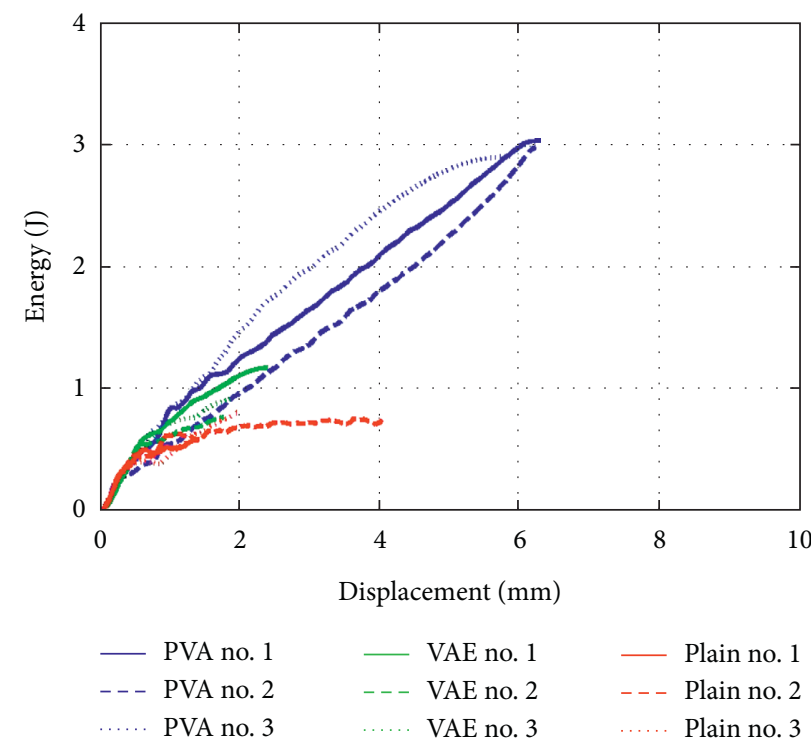

(c)

Figure 7: Comparison of relationship between impact fracture energy and displacement at the selected temperature conditions. (a) $-70^{\circ} \mathrm{C}$. (b) $70^{\circ} \mathrm{C}$. (c) $140^{\circ} \mathrm{C}$.

polymers in order to suppress local failure due to impact load $[22,25,47]$. Figure 6 shows the type of fracture due to the typical impact on the specimen. The fractures can be classified into three types based on the observation of the specimen with the naked eyes after impact: (1) penetration, (2) scabbing, and (3) perforation. Penetration refers to the occurrence of microcracks and deformation plastically in the rear as a result of impact to specimens. In case of scabbing, it is estimated that spalling or macrocracks occur in the rear due to impact of specimens; in perforation, it is assumed that specimens are completely perforated.

Table 8 shows the overhead failure pattern of the front and rear face of the specimens under low-velocity impact loading at the selected temperature conditions of $-70^{\circ} \mathrm{C}$, $70^{\circ} \mathrm{C}$, and $140^{\circ} \mathrm{C}$ as obtained from the low-velocity impact test results. Among the 27 specimens, 20 specimens were observed to be fully perforated and were broken into three or more pieces. In case of the specimens of PAFRC composite, perforation failure did not occur except the specimens no. 1 and no. 2 at $140^{\circ} \mathrm{C}$, while the rear face was suppressed, so that the difference in impact resistance capacity could be visually observed. Regardless of the selected temperature conditions, the rear face shows a pattern of the widening and propagation cracks in the vertical or inclined direction at the center of the impact point. As a result, more widening cracks occurred in the rear than in the front face. It is considered that the propagation of cracks is delayed at the fracture owing to PVA fiber reinforcement. On the other hand, the specimens of VAEPC composite were fractured and perforated almost vertically or in the inclined direction at the 


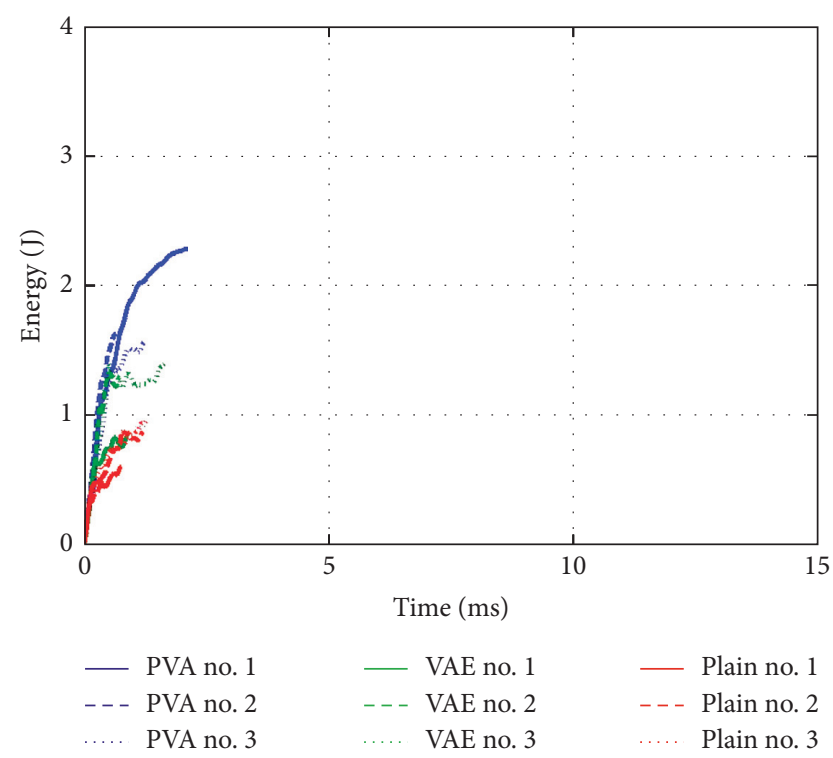

(a)

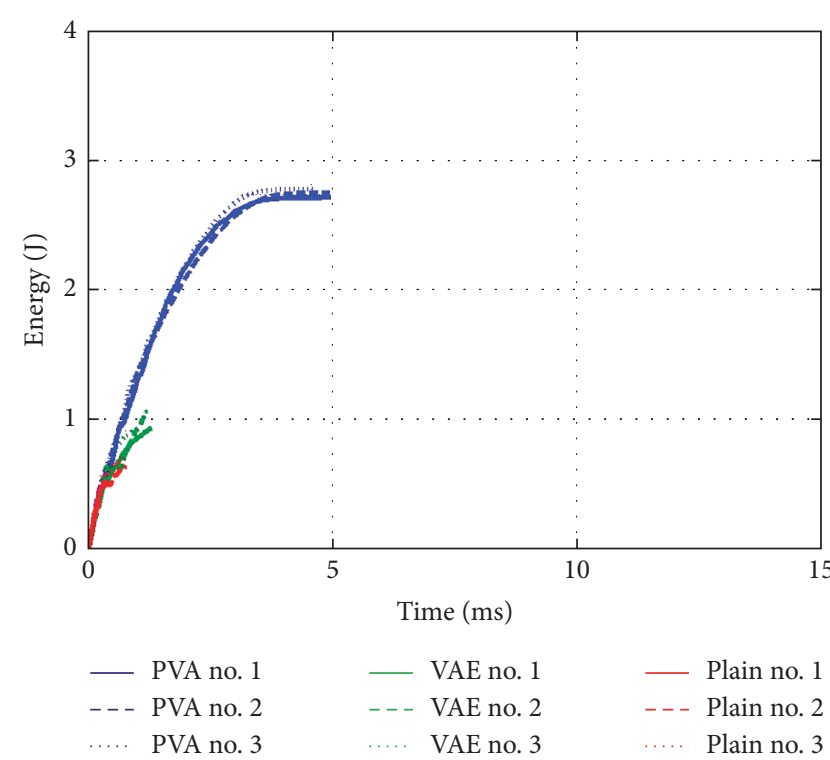

(b)

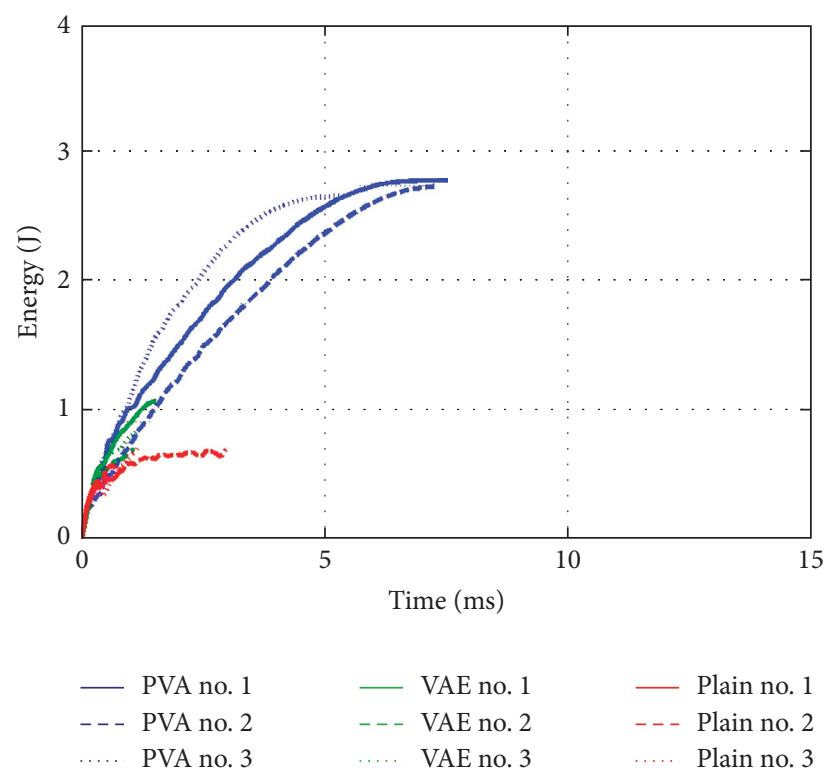

(c)

FIGURE 8: Comparison of relationship between impact fracture energy and time at the selected temperature conditions. (a) $-70^{\circ} \mathrm{C}$. (b) $70^{\circ} \mathrm{C}$. (c) $140^{\circ} \mathrm{C}$.

center of the impact point in both rear and front faces of the specimens in a similar way. At the temperature of $70^{\circ} \mathrm{C}$, no. 1 specimen showed a brittle fracture behavior due to the fallout of the rear face, and some fragments could not be identified as the debris was ruptured, while the specimens of plain mortar showed cracks all in the vertical or inclined direction from the center regardless of the temperature conditions, and the perforation failure occurred with a comparatively large number of fragments suggesting that the degree of improvement in the impact resistance capacity is the lowest. And the specimen no. 2 at $-70^{\circ} \mathrm{C}$, the specimens no. 1 , no. 2 at $70^{\circ} \mathrm{C}$, and the specimens no. 1 , no. 3 at $140^{\circ} \mathrm{C}$ temperature condition were peeled off in the rear face and fractured into the spalling. Therefore, the specimens of PAFRC composite are expected to be able to realize high safety performance for the facilities in case of high rapid loads such as collisions, impacts, and explosions.

3.2.2. Characteristics of Impact Fracture Energy. Table 9 shows the results data of the low-velocity impact tests under the selected temperature conditions of $-70^{\circ} \mathrm{C}, 70^{\circ} \mathrm{C}$, and $140^{\circ} \mathrm{C}$. As for the specimens of PAFRC composite, the impact fracture energy up to peak load of each specimen was $0.94 \mathrm{~J}, 0.78 \mathrm{~J}$, and $1.15 \mathrm{~J}$, respectively, at $-70^{\circ} \mathrm{C}$, and the average impact fracture energy was $0.95 \mathrm{~J}$. The impact fracture 

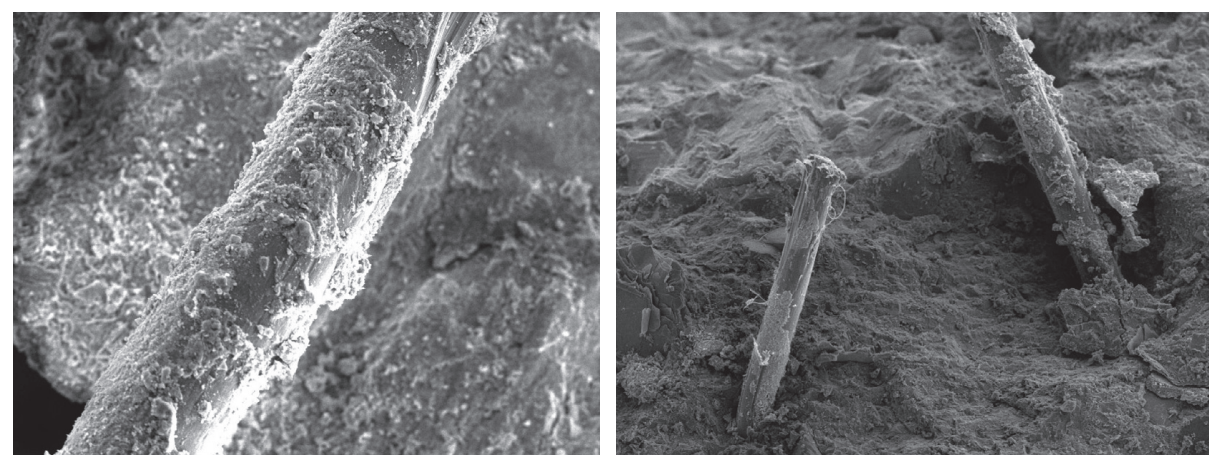

(a)

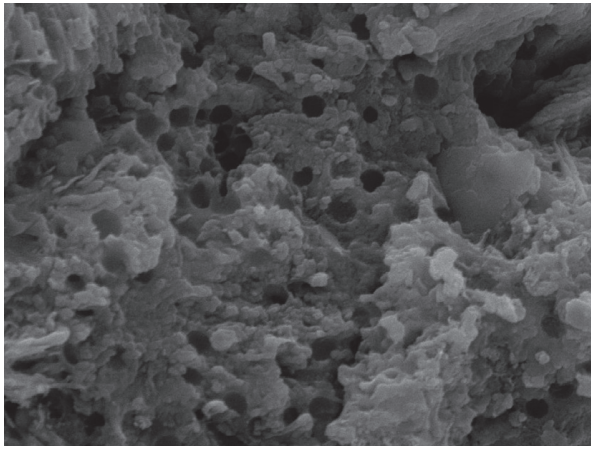

(b)

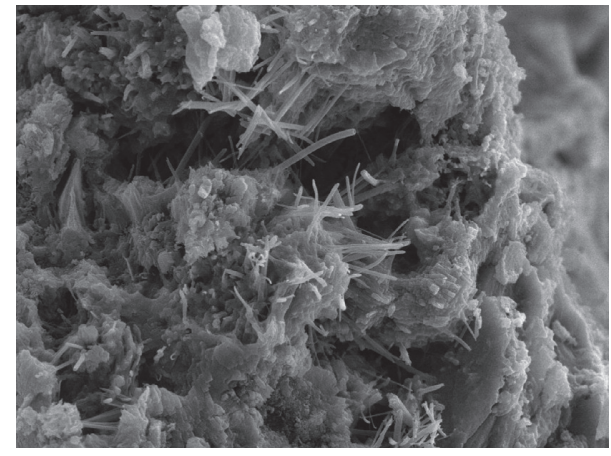

(c)

Figure 9: SEM images of mortar. (a) PVA fiber. (b) VAE polymer. (c) Plain mortar.

energy up to peak load of each specimen at $70^{\circ} \mathrm{C}$ was $0.91 \mathrm{~J}$, $0.20 \mathrm{~J}$, and $0.19 \mathrm{~J}$, respectively, and the average impact fracture energy resulted in $0.43 \mathrm{~J}$. On the other hand, the impact fracture energy up to peak load of each specimen at the temperature of $140^{\circ} \mathrm{C}$ was $0.71 \mathrm{~J}, 0.13 \mathrm{~J}$, and $0.18 \mathrm{~J}$, and the average impact fracture energy turned out to be $0.34 \mathrm{~J}$. In case of the specimens of VAEPC composite, however, the impact fracture energy up to peak load of each specimen was $0.63 \mathrm{~J}, 0.89 \mathrm{~J}$, and $1.16 \mathrm{~J}$ at $-70^{\circ} \mathrm{C}$, and the impact fracture energy in average was $0.89 \mathrm{~J}$. The impact fracture energy up to peak load of each specimen at $70^{\circ} \mathrm{C}$ was $0.11 \mathrm{~J}, 0.49 \mathrm{~J}$, and $0.22 \mathrm{~J}$, respectively, and the average impact fracture energy was $0.27 \mathrm{~J}$. Besides, the impact fracture energy up to peak load of each specimen at $140^{\circ} \mathrm{C}$ was $0.43 \mathrm{~J}, 0.42 \mathrm{~J}$, and $0.18 \mathrm{~J}$, respectively, and the average impact fracture energy was $0.34 \mathrm{~J}$, while the impact fracture energy up to peak load of each specimen in plain mortar was $0.18 \mathrm{~J}, 0.18 \mathrm{~J}$, and $0.20 \mathrm{~J}$ at $-70^{\circ} \mathrm{C}$, and the average impact fracture energy was $0.19 \mathrm{~J}$. At the temperature of $70^{\circ} \mathrm{C}$, the impact fracture energy up to peak load of each specimen was $0.43 \mathrm{~J}, 0.15 \mathrm{~J}$, and $0.50 \mathrm{~J}$, and the average impact fracture energy was found to be $0.36 \mathrm{~J}$. Furthermore, at the ultimate temperature of $140^{\circ} \mathrm{C}$, the impact fracture energy up to peak load of each specimen was $0.17 \mathrm{~J}, 0.16 \mathrm{~J}$, and $0.18 \mathrm{~J}$, and the average impact fracture energy was $0.17 \mathrm{~J}$. As a result, it was made known that the specimens of PAFRC composite generated the greatest amount of total energy of all at the selected temperature conditions of $-70^{\circ} \mathrm{C}, 70^{\circ} \mathrm{C}$, and $140^{\circ} \mathrm{C}$. In contrast, the specimens of plain mortar (PM) have shown remarkable decline in total energy. The reason why such greatest amount of total energy was caused seems due to the bridging effect of PVA fiber. The total impact fracture energy was highest for PAFRC in the order of PAFRC $>$ VAEPC $>$ plain mortar. Meanwhile, the impact fracture energy of all specimens decreased in parallel with increasing temperature. The specimens of PAFRC composite showed the highest values at $70^{\circ} \mathrm{C}$ and $140^{\circ} \mathrm{C}$, and those of plain mortar featured the lower values at $70^{\circ} \mathrm{C}$.

3.2.3. Relationship between Impact Fracture Energy and Displacement. Figure 7 shows the relationship between impact fracture energy and displacement at the selected temperature conditions of $-70^{\circ} \mathrm{C}, 70^{\circ} \mathrm{C}$, and $140^{\circ} \mathrm{C}$. According to the low-velocity impact tests, the impact fracture energy of the specimens of PAFRC composite indicated more displacement together with the greatest amount of total energy in respect to external impact than the other specimens. This shows that the impact fracture energy of PVA fiber is higher than that of other specimens when the impact load is applied, and the displacement increased greatly while maintaining the impact fracture energy for a long time. On the other hand, the specimens of VAEPC composite and plain mortar were shown to have an abrupt brittle fracture behavior and their displacement tended to decrease almost in a similar way. This is possible by the bridging of fibers across the cracks, which helps improve the energy absorption capacity due to PVA fiber reinforcement. In addition, at the temperature of $140^{\circ} \mathrm{C}$, the displacement of the specimens of PAFRC composite increased the most, and 
it was significantly more ductile than the other specimens. At the temperature of $-70^{\circ} \mathrm{C}$, all specimens showed the least displacement, more brittle, and lower impact fracture energy.

\subsubsection{Relationship between Impact Fracture Energy and} Time. Figure 8 shows the relationship between the impact fracture energy and time at the selected temperature conditions of $-70^{\circ} \mathrm{C}, 70^{\circ} \mathrm{C}$, and $140^{\circ} \mathrm{C}$. In the low-velocity impact tests, the impact fracture behavior of the specimens of PAFRC composite showed almost linear elastic behavior in the initial stage but later showed nonlinear behavior. For the specimens of PAFRC composite, it has the longest time and the greatest amount of total energy due to the bridging effect of PVA fibers compared to other specimens at the temperature of $140^{\circ} \mathrm{C}$. This is believed attributable to the fact that the transition occurred from the brittle to the ductile fracture but the fracture was not complete and the impact energy was absorbed in part. On the other hand, the specimens of VAEPC composite and plain mortar showed almost similar tendency. It was also found that the time of the specimens of PAFRC composite was longest at the temperature of $140^{\circ} \mathrm{C}$. Especially at the temperature of $-70^{\circ} \mathrm{C}$, all specimens showed the fastest time, and the impact fracture energy was the lowest with brittleness.

3.2.5. SEM Observation. Figure 9 displays the images of the fractured surface condition observed after the low-velocity impact tests of the specimen with SEM. As seen in Figure $9(\mathrm{a})$, the cement hydrate of large and small particles was formed on the surface of PAFRC composites, and fiber pullout occurred between the matrices since spacing within the fiber was widened and thus affinity grew stronger. This shows that the failure mechanism is activated mainly due to fiber pullout, rather than fiber fracture. In case of VAEPC composites, as shown in Figure 9(b), the polymer film once formed fills the pores between the cement hydrate and the aggregate, revealing a very clean and quite smooth surface owing to tight internal structure and improved interfacial bonding. It was found, however, that somewhat fine pores were formed on the fractured surface. It may be said therefore that PVA fiber demonstrates a better interfacial bonding than the plain mortar. The reason is because, in case of plain mortar, the internal structure ability is broken and formation of cement hydrate is insufficient, whereas lots of cement hydrate are formed on the surface of PVA fiber.

\section{Conclusions}

In the study, the compressive and flexural properties of the VAEPC and the PAFRC composites and plain mortar were compared and analyzed. Their impact resistance performance under low-velocity impact loading at the selected temperature conditions of $-70^{\circ} \mathrm{C}, 70^{\circ} \mathrm{C}$, and $140^{\circ} \mathrm{C}$ was evaluated. From the experiments performed in the paper, the following conclusions were drawn:

(1) The compressive strength of PAFRC composites at 28 days of age was usually almost that of plain mortar, and VAEPC composites were somewhat reduced, while the flexural strength at 28 days of age was found to be significantly improved in PAFRC and VAEPC composites compared to plain mortar.

(2) As the results of tests showed, PAFRC composites produced the height flexural stress compared with VAEPC composites and plain mortar, and they revealed the tendency to elevate the flexural performance thanks to increased amount of displacement and getting larger after the final failure.

(3) The PAFRC resists relatively better against impact because it contains the PVA fiber which acts as a bridge to suppress crack propagation and to improve energy absorption performance.

(4) The specimens of PAFRC composite were observed to some extent to suppress the perforation failures while the VAEPC composite and the plain mortar were destroyed in a form of being perforated.

(5) So it is found that, under a load of low-velocity impact, the resistance performance of the VAEPC composite and the plain mortar was proven to show brittle fracture behavior, while the PAFRC showed ductile fracture behavior in virtue of PVA fiber reinforcement which improved its flexural performance.

(6) According to the SEM observation which followed the tests, the PAFRC composite as a fiber-reinforced material of the hydrophilic material was found to show the most excellent interfacial bond adhesion compared to the other composite and the plain mortar.

Therefore, the PAFRC composite manufactured in the study has been proven to be very useful as a reinforcement material in both high and low temperature environments.

\section{Data Availability}

The data used to support the findings of this study are available from the corresponding author upon request.

\section{Conflicts of Interest}

The authors declare that there are no conflicts of interest regarding the publication of this paper.

\section{Acknowledgments}

This research was supported by Basic Science Research Program through the National Research Foundation of Korea (NRF) funded by the Ministry of Education (Grant no. NRF-2018R1A6A1A03025542).

\section{References}

[1] A. A. Deshpande, D. Kumar, and R. Ranade, "Influence of high temperatures on the residual mechanical properties of a hybrid fiber-reinforced strain-hardening cementitious composite," Construction and Building Materials, vol. 208, pp. 283-295, 2019. 
[2] Q. Ma, R. Guo, Z. Zhao, Z. Lin, and K. He, "Mechanical properties of concrete at high temperature-A review," Construction and Building Materials, vol. 93, pp. 371-383, 2015.

[3] A. M. Brandt, "Fibre reinforced cement-based (FRC) composites after over 40 years of development in building and civil engineering," Composite Structures, vol. 86, no. 1-3, pp. 3-9, 2008.

[4] D. J. Kim, A. E. Naaman, and S. EL-Tawil, "Comparative flexural behavior of four fiber reinforced cementitious composites," $\mathrm{Ce}$ ment and Concrete Composites, vol. 30, no. 10, pp. 917-928, 2008.

[5] J. P. Ronualdi and B. V. Batson, "Fiber reinforced concrete properties," Journal of Engineering Mechanics Division, vol. 89, no. 3, pp. 147-168, 1963.

[6] N. Banthia, F. Majdzadeh, J. Wu, and V. Bindiganavile, "Fiber synergy in hybrid fiber reinforced concrete (HyFRC) in flexure and direct shear," Cement and Concrete Composites, vol. 48, no. 4, pp. 91-97, 2014.

[7] P. Chen and D. D. L. Chung, "A comparative study of concretes reinforced with carbon, polyethylene, and steel fibers and their improvement by latex addition," ACI Materials Journal, vol. 93, no. 2, pp. 129-133, 1996.

[8] P. L. Waton and A. J. Majumdar, "Cement-based composites with mixtures of different types of fiber," Composites, vol. 6, no. 5, pp. 209-216, 1975.

[9] R. F. Zollo, "Fiber-reinforced concrete: an overview after 30 years of development," Cement and Concrete Composites, vol. 19, no. 2, pp. 107-122, 1997.

[10] B. Mobasher and C. Y. Li, "Mechanical properties of hybrid cement-based composites," ACI Materials Journal, vol. 93, no. 3, pp. 284-292, 1996.

[11] J. Zhang, J. Leung, and Y. N. Cheung, "Flexural performance of layered ECC-concrete composite beam," Composites Science and Technology, vol. 66, no. 11-12, pp. 483-492, 2006.

[12] C. C. Thong, D. C. L. Teo, and C. K. Ng, "Application of polyvinyl alcohol (PVA) in cement-based composite materials: a review of its engineering properties and microstructure behavior," Construction and Building Materials, vol. 107, pp. 172-180, 2016.

[13] J.-G. Choi, G.-C. Lee, K.-T. Ko, and G.-S. Ryu, "Effect of VAE type powder polymer on strength properties of high strength polymer cement mortars," Journal of the Korea Institute of Building Construction, vol. 15, no. 3, pp. 299-306, 2015.

[14] K. H. Min, J. Y. Lee, M. H. Kim, and Y. S. Yoon, "Behaviors of concrete segmented composites using polymer mortar under static and impact loadings," Journal of the Korea Institute for Structural Maintenance and Inspection, vol. 15, no. 5, pp. 169-177, 2011.

[15] Y. Shao and S. P. Shah, "Mechanical properties of PVA fiber reinforced cement composites fabricated by extrusion processing," ACI Materials Journal, vol. 94, no. 3, pp. 555-564, 1997.

[16] A. Goswami, S. D. Adhikary, and B. Li, "Predicting the punching shear failure of concrete slabs under low velocity impact loading," Engineering Structures, vol. 184, pp. 37-51, 2019.

[17] D. Y. You and N. Banthia, "Impact resistance of fiber-reinforced concrete-a review," Cement and Concrete Composites, vol. 104, Article ID 103389, 2019.

[18] G. Baloevic, J. Radnic, D. Matesan, and N. Grgic, "Behavior of fiber reinforced mortar composites under impact load," Latin American Journal of Solids and Structures, vol. 15, no. 2, pp. 1-13, 2017.

[19] J. Radnić, D. Matešan, N. Grgić, and G. Baloević, "Impact testing of RC slabs strengthened with CFRP strips," Composite Structures, vol. 121, pp. 90-103, 2015.

[20] S.-H. Han, G.-Y. Kim, H.-S. Kim, J.-H. Kim, and J.-S. Nam, "Evaluation on rear fracture reduction and crack properties of cement composites with high-velocity projectile impact by fiber types," Journal of the Korea Concrete Institute, vol. 27, no. 2, pp. 157-167, 2015.
[21] S. Liu, D. Zhu, G. Li et al., "Flexural response of basalt textile reinforced concrete with pre-tension and short fibers under low-velocity impact loads," Construction and Building Materials, vol. 169, pp. 859-876, 2018.

[22] S. Mindess, A. Bentur, C. Yan, and G. Vondran, "Impact resistance of concrete containing both conventional steel reinforcement and fibrillated polypropylene fibers," $A C I$ Materials Journal, vol. 86, no. 6, pp. 545-549, 1989.

[23] Ş. Yazici, H. Ş. Arel, and V. Tabak, "The effects of impact loading on the mechanical properties the SFRCs," Construction and Building Materials, vol. 41, pp. 68-72, 2013.

[24] S.-Y. Lee, G.-D. Kim, S. J. Kim, and C.-H. Chang, "Highenergy impact behaviors of hybrid composite plates strengthened with 3D-UHMWPE composites," Shock and Vibration, vol. 2018, Article ID 7626075, 11 pages, 2018.

[25] V. Bindiganavile and N. Banthia, "Polymer and steel fiberreinforced cementitious composites under impact loadingpart 2: flexural toughness," ACI Materials Journal, vol. 98, no. 1, pp. 17-24, 2001.

[26] V. Bindiganavile, N. Banthia, and B. Aarup, "Impact response of ultra-high-strength fiber-reinforced cement composites," ACI Materials Journal, vol. 99, no. 6, pp. 543-548, 2002.

[27] Y. Mohammaad, R. Carkon-A, S. P. Singh, and S. K. Kaushik, "Impact resistance of steel fibrous concrete containing fibrous of mixed aspect ratio," Construction and Building Materials, vol. 23, no. 1, pp. 183-189, 2009.

[28] K. Habel, E. Denarié, and E. Brühwiler, "Experimental investigation of composite ultra-high performance fiber-reinforced concrete and conventional concrete members," ACI Structural Journal, vol. 104, no. 1, pp. 93-101, 2007.

[29] K. Habel and P. Gauvreau, "Response of ultra-high performance fiber reinforced concrete (UHPFRC) to impact and static loading," Cement and Concrete Composites, vol. 30, no. 10, pp. 938-946, 2008.

[30] K. Hannawi, H. Bian, W. Prince-Agbodjan, and B. Raghavan, "Effect of different types of fibers on the microstructure and the mechanical behavior of Ultra-High Performance FiberReinforced Concretes," Composites Part B: Engineering, vol. 86, pp. 214-220, 2016.

[31] Z. Rong, W. Sun, H. Xiao, and G. Jiang, "Effects of nano-SiO2 particles on the mechanical and microstructural properties of ultra-high performance cementitious composites," Cement and Concrete Composites, vol. 56, pp. 25-31, 2015.

[32] V. C. Li, "On engineered cementitious composites (ECC)," Journal of Advanced Concrete Technology, vol. 1, no. 3, pp. 215-230, 2003.

[33] V. C. Li, S. Wang, and C. Wu, "Tensile strain-hardening behavior of polyvinyl alcohol engineered cementitious composites (PVA-ECC)," ACI Materials Journal, vol. 98, no. 6, pp. 483-492, 2001.

[34] Y.-W. Kim, K.-H. Min, J.-M. Yang, and Y.-S. Yoon, "Flexural and impact resisting performance of HPFRCCs using hybrid PVA fibers," Journal of the Korea Concrete Institute, vol. 21, no. 6, pp. 705-712, 2009.

[35] K.-R. Wu, D. Zhang, and J.-M. Song, "Properties of polymermodified cement mortar using pre-enveloping method," Cement and Concrete Research, vol. 32, no. 3, pp. 425-429, 2002.

[36] M. U. K. Afridi, Y. Ohama, K. Demura, and M. Z. Iqbal, "Development of polymer films by the coalescence of polymer particles in powdered and aqueous polymer-modified mortars," Cement and Concrete Research, vol. 33, no. 11, pp. 1715-1721, 2003.

[37] R. W. Poston, K. E. Kesner, A. M. Vaysburd, and P. H. Emmons, "Concrete repair material performance-laboratory study," $A C I$ Materials Journal, vol. 98, no. 2, pp. 137-147, 2001. 
[38] Y. Ohama, K. Demure, M. Hamatsu, and M. Kakegawa, "Properties of polymer-modified mortars using styrene-butyl acrylate latexes with various monomer ratios," ACI Materials Journal, vol. 88, no. 1, pp. 56-61, 1991.

[39] N. Banthia, C. Yan, and K. Sakai, "Impact resistance of fiber reinforced concrete at subnorma temperatures," Cement and Concrete Composites, vol. 20, no. 5, pp. 393-404, 1998.

[40] S. Liu, P. Rawat, X. Wang, and D. Zhu, "Low velocity impact behavior of AR-glass textile reinforced mortar under varing range of loading and temperatures," Construction and Building Materials, vol. 228, pp. 1-12, 2019.

[41] S. Kim and C. Park, "Flexural behavior characteristics of high performance slurry infiltrated fiber reinforced cementitious composite with respect to exposure to high temperature," Journal of the Korea Concrete Institute, vol. 31, no. 2, pp. 139-146, 2019.

[42] U. A. Khashaba and R. Othman, "Low-velocity impact of woven CFRE composites under different temperature levels," International Journal of Impact Engineering, vol. 108, pp. 191-204, 2017.

[43] X. Liang, C. Wu, Y. Yang, C. Wu, and Z. Li, "Coupled effect of temperature and impact loading on tensile strength of ultrahigh performance fibre reinforced concrete," Composites Structures, vol. 229, pp. 1-9, 2019.

[44] American Society for Testing Materials, ASTM C1018-97: Standard Test Method for Flexural Toughness and First Crack Strength of Fiber-Reinforced Concrete (Using Beam with Thirdpoint Loading), American Society for Testing Materials, West Conshohocken, PA, USA, 1998.

[45] Korean Standards Association, KSL ISO 679: Methods of Testing Cements-Determination of Strength, Korean Standards Association, Seoul, South Korea, 2006.

[46] R. Yu, P. Spiesz, and H. J. H. Brouwers, "Energy absorption capacity of a sustainable Ultra-High Performance Fibre Reinforced Concrete (UHPFRC) in quasi-static mode and under high velocity projectile impact," Cement and Concrete Composites, vol. 68, pp. 109-122, 2016.

[47] J.-Y. Min, H.-W. Cho, J.-H. Lee, S.-W. Kim, and J.-H. Moon, "Evaluation of fracture behaviours of cementitious composites by high-velocity projectile impact," Journal of the Korea Institute for Structural Maintenance and Inspection, vol. 19, no. 6, pp. 55-62, 2015. 